\title{
Pulmonary Surfactant Disaturated- Phosphatidylcholine (DSPC) Turnover and Pool Size in Newborn Infants with Congenital Diaphragmatic Hernia (CDH)
}

\author{
PAOLA E. COGO, LUC J.I. ZIMMERMANN, LUISA MENEGHINI, NICOLETTA MAININI, \\ LINDA BORDIGNON, VINCENZO SUMA, MARIKA BUFFO, AND VIRGILIO P. CARNIELLI \\ Department of Pediatrics, University of Padova, IT-35123 Padova, Italy [P.E.C., N.M., L.B., M.B.]; \\ Neonatal Intensive Care, Erasmus University, NL-3015 Rotterdam, The Netherlands [L.J.I.Z.]; Institute of \\ Anaesthesia and Critical Care, University of Padova, IT-35123 Padova, Italy [L.M., V.S.]; Neonatal \\ Medicine, "G.Salesi” Hospital, IT-30123 Ancona, Italy [V.P.C.]
}

\begin{abstract}
In animal $\mathrm{CDH}$ models, surfactant deficiency contributes to the pathophysiology of the condition but information on human disease is very limited. The aim of our study was to investigate surfactant kinetics in $\mathrm{CDH}$ newborns. We studied surfactant disaturated-phosphatidylcholine (DSPC) half-life, turnover and apparent pool size by stable isotope methodology in CDH newborns with no ExtraCorporeal Membrane Oxygenation (ECMO) support ( $n=13$, birth weight (BW) $3.2 \pm 2.2 \mathrm{~kg}$, gestational age (GA) $39 \pm 0.4 \mathrm{wks}$, postnatal age $43 \pm 11 \mathrm{~h}$ ) and in 8 term infants with no lung disease (CONTROLS, BW $2.7 \pm 0 \mathrm{~kg}$, GA $38 \pm 0.8$ wks, postnatal age $96 \pm 26 \mathrm{~h}$ ). We administered a trace dose of ${ }^{13} \mathrm{C}$-palmitic acid dipalmitoyl-phosphatidylcholine (DPPC) through the endotracheal (ET) tube and we measured DSPC kinetics by gas chromatography-mass spectrometry from $\mathrm{DSPC}^{13} \mathrm{C}$-enrichment decay curves obtained from sequential tracheal aspirates. DSPC amount from tracheal aspirates (TA-DSPC) was measured by gas chromatography. In CDH infants DSPC half-life was shorter $(24 \pm 4$ and $53 \pm 11 \mathrm{~h}, p=0.01)$, turnover faster $(0.6 \pm 0.1$ and $\left.1.5 \pm 0.3 \mathrm{~d}^{-1} p=0.01\right)$, apparent pool size smaller $(34 \pm 6$ and $57 \pm 7 \mathrm{mg} / \mathrm{kg}$ body weight, $p=0.02$ ) and tracheal aspirates DSPC amount lower $(2.4 \pm 0.4$ and $4.6 \pm 0.5 \mathrm{mg} / \mathrm{mL}$ Epithelial Lining Fluid (ELF), $p=0.007$ ) than in CONTROLS. In conclusion surfactant kinetics is grossly abnormal in mechanically ventilated $\mathrm{CDH}$. Whether alterations of DSPC kinetics in $\mathrm{CDH}$ infants are caused by a primary surfactant deficiency or are secondary to
\end{abstract}

\section{ABSTRACT}

oxygen therapy and ventilator support has still to be determined.

(Pediatr Res 54: 653-658, 2003)

Abbreviations
CDH, congenital diaphragmatic hernia
DSPC, disaturated-phosphatidylcholine

ECMO, extra-corporeal membrane oxygenation

TA-DSPC, tracheal aspirate disaturated-phosphatidylcholine

ELF, epithelial lining fluid

PC, phosphatidylcholine

MAS, meconium aspiration syndrome

SP-A, surfactant protein A

Fio $_{2}$, fraction inspired oxygen

HFOV, high frequency oscillatory ventilation

DPPC, phosphatidylcholine-phosphatidylcholine

[U- $\left.{ }^{13} \mathbf{C}-\mathbf{P A}\right]-D P P C$, uniformly ${ }^{13} \mathrm{C}$ palmitic acid

phosphatidylcholine-phosphatidylcholine

PA, palmitic acid

MPE, mole percent excess

ET, endotracheal

GA, gestational age

BW, birth weight

FSR, fractional synthesis rate

ASR, absolute synthesis rate

BPD, bronchopulmonary dysplasia

RDS, respiratory distress syndrome
Clinical and animal studies using air pressure-volume data showed that $\mathrm{CDH}$ lungs are significantly less compliant than

Received November 18, 2002; accepted February 3, 2003.

Correspondence: Paola E. Cogo, Dipartimento di Pediatria, Universita' di Padova, Via Giustiniani 3, 35123 Padova, Italy; e-mail: paolac@child.pedi.unipd.it

The study was run with the core funding of Nutrition and Metabolism laboratory, Department of Pediatrics, University of Padova, Italy.

DOI: 10.1203/01.PDR.0000084344.42409.C6 normal lungs. This finding can be related to lung immaturity, surfactant deficiency, to changes in the amount of collagen and elastic fibers or to lung damage induced by mechanical ventilation (1-3). High-inspired oxygen fraction $\left(\mathrm{Fio}_{2}\right)$ and positive pressure ventilation may also induce secondary surfactant inactivation and altered surfactant function.

It is still unclear whether a primary surfactant deficiency is present in human $\mathrm{CDH}$. $\mathrm{CDH}$ animal models showed reduced 
amounts of DSPC and of surfactant Protein A (SP-A) in lung tissue but no alteration of the amniotic lecithin/sphingomyelin $(\mathrm{L} / \mathrm{S})$ ratio (4-7). However $\mathrm{CDH}$ animal models have several limitations. Nitrofen fed pregnant rat mothers produces $\mathrm{CDH}$ in about $80 \%$ of fetuses $(4,8)$. Interestingly studies applying this method showed structural and biochemical immaturity also in pup lungs that did not develop $\mathrm{CDH}$, raising the concern that Nitrofen exposed rats fetuses may develop lung hypoplasia independently from the occurrence of $\mathrm{CDH}$ and therefore by a mechanism different from that occurring in humans $(5,7)$. Surgical CDH models have also been developed in lambs, where $\mathrm{CDH}$ is induced by excision of a portion of fetal diaphragm at a relative late time of gestation compared with the human condition $(4,9-12)$.

Data in human $\mathrm{CDH}$ come mainly from the histologic studies although their interpretation is complicated by the presence of structural changes induced by mechanical ventilation. It has been observed in 17 autopsy cases of CDH associated pulmonary hypoplasia that the lung of the affected side is less developed than the contralateral one and that DSPC content is markedly lower in the affected side compared with the contralateral lung and to control lungs (13).

A recent study, in mechanically ventilated infants, reports similar concentrations of phosphatidylcholine (PC), phosphatidylglycerol and L/S ratios from bronchoalveolar lavage fluid of $\mathrm{CDH}$ and of age matched control infants, suggesting that a primary surfactant deficiency is unlikely in infants with $\mathrm{CDH}$ (14). An even more recent study (15) showed similar PC half-life and pool size in CDH newborns who required ECMO support, compared with $\mathrm{CDH}$ newborns not treated with ECMO and with newborns with meconium aspiration syndrome (MAS). It is noteworthy that patients studied by Janssen et al. had all severe respiratory failure (15). In the present study by applying a stable isotope tracer methodology (16) we studied DSPC half-life, turnover and apparent pool size in mechanically ventilated newborn infants with $\mathrm{CDH}$ and in newborn infants, who were on mechanical ventilation but had normal lungs.

\section{MATERIALS AND METHODS}

Patients. Mechanically ventilated newborn infants with $\mathrm{CDH}$ and not requiring ECMO at any time during their hospital stay $(\mathrm{CDH})$ and newborn infants who were on mechanical ventilation but had normal lungs (CONTROLS). CONTROLS required endotracheal intubation for upper airways malformations, abdominal wall defects or neuro-muscular diseases. All patients were admitted either to the Neonatal or to the Pediatric Intensive Care Unit of the Department of Pediatrics, University of Padua. The study protocol was approved by the local Ethics Committee, and written informed parental consent was obtained for each study infant.

CDH Infants. Inclusion criteria were: 1) respiratory failure requiring endotracheal intubation, 2) written informed consent from parents, 3) no exogenous surfactant administered 4) no chromosomal abnormalities.

CONTROL infants. Full term infants who required mechanical ventilation for surgery, airways malformations or neuro- muscular diseases during the first week of life. Inclusion criteria were: 1) no history of lung disease, 2) normal chest radiograph, 3) fraction inspired oxygen $\left(\mathrm{Fio}_{2}\right)$ of less than $30 \%$ at any time during the study period, 4) written informed consent from parents 5) no clinical or biochemical evidence of infection.

Study design. All CDH infants were ventilated with High Frequency Oscillatory Ventilation (HFOV) from birth apart from one who received conventional ventilation. Management of $\mathrm{CDH}$ in our unit included HFOV, i.v. infusion of midazolam, fentanyl and vecuronium and enteral feeding as soon as tolerated. Time of surgery was postponed until hemodynamic stability was achieved. Ventilator parameters and $\mathrm{FiO}_{2}$ were adjusted so that the preductal oxygen saturation was greater than $90 \%$ and the $\mathrm{Pco}_{2}$ from 40 to $50 \mathrm{~mm} \mathrm{Hg}$. CONTROLS were either on mechanical ventilation or breathing spontaneously through a tracheostomy tube. Ventilator parameters for both groups were recorded before the start of the study and every $6 \mathrm{~h}$ thereafter. The oxygenation index (OI) was calculated as $\mathrm{MAPxFio}{ }_{2} / \mathrm{Pao}_{2}$ where MAP represented Mean Airway Pressure.

All CDH and CONTROLS received an endotracheal tracer dose of $5 \mathrm{mg} / \mathrm{kg}$ of $\left[\mathrm{U}_{-}{ }^{13} \mathrm{C}-\mathrm{PA}\right]-\mathrm{DPPC}$ to trace pulmonary surfactant DSPC. Both palmitic acids (PA) of the tracer molecule were uniformly labeled with the stable isotope carbon-13 (Martek Biosciences, Columbia, MD, U.S.A.) and $\left[\mathrm{U}_{-}{ }^{13} \mathrm{C}-\right.$ PA]-DPPC was prepared and administered as previously described $(16,17)$. Briefly at the time of the study the tracer was towed and mixed with small amount of porcine surfactant (Curosurf, Chiesi Farmaceutici S.p.a, Parma, Italy) diluted in normal saline (Phospholipid concentration $10 \mathrm{mg} / \mathrm{mL}$ ) and warmed to body temperature before endotracheal administration. Total administered volume was $0.3 \mathrm{~mL} / \mathrm{kg}$ body weight. The tracer was administered as follows: after routine endotracheal suctioning, a 6-French catheter was placed beyond the tip of the ET tube. Pre warmed tracer was administered via the catheter, followed by $1 \mathrm{~mL}$ of normal saline. The neonate was bag ventilated for 3-5 breaths and then immediately reconnected to the ventilator at pretreatment settings.

Tracheal aspirates (TAs) were collected before the tracer administration (time 0 ) and then every $6 \mathrm{~h}$ until $72 \mathrm{~h}$ and every $12 \mathrm{~h}$ thereafter until extubation.

Samples and analytical methods. Methods of collection and storage of tracheal aspirates have been reported elsewhere (16). One $\mathrm{mL}$ of normal saline was instilled in the endotracheal tube, followed by collection of TA in a Lukens trap. Sample was kept at $+5^{\circ} \mathrm{C}$ and processed within $3 \mathrm{~h}$. It was gently vortexed and then centrifuged at $400 \mathrm{~g}$ per $10 \mathrm{~min}$ to discard mucus and cells and kept at $-20^{\circ} \mathrm{C}$ until analysis.

DSPC analysis had been described previously (16). Briefly, after extraction by Bligh and Dyer (18), DSPC from TAs was purified by thin layer chromatography with osmium tetroxide. DSPC amount was calculated by measuring the individual fatty acids by capillary gas chromatography. By this method saturated fatty acids comprised more than $98 \%$ of the fatty acid composition in all study infants (16). DSPC amount from TAs was expressed in $\mathrm{mg} / \mathrm{mL}$ ELF after correction with the urea method (19). Dilution of ELF was calculated as ELF volume 
(per $\mathrm{mL}$ of return fluid from TAs $)=\left([\text { urea }]_{\mathrm{TA}} /[\text { urea }]_{\text {PLASMA }}\right)$. The enrichment of [U- $\left.{ }^{13} \mathrm{C}-\mathrm{PA}\right]$-DSPC from the TAs was measured by gas chromatography-mass spectrometry and results expressed in mol percent excess (MPE) as previously reported $(16,20)$.

Surfactant kinetic parameters. The $\left[\mathrm{U}_{-}{ }^{13} \mathrm{C}-\mathrm{PA}\right]-\mathrm{DSPC}$ halflife and apparent DSPC pool size were calculated from the mono exponential part of the DSPC decay enrichment curve over time $(16,21,22)$. The software used for calculation of DSPC kinetics was Prism v. 3.0 by Graph Pad Software Inc. San Diego, CA. Extrapolation back to the time of the administration of the tracer $(t=0)$ represented the ${ }^{13} \mathrm{C}$ enrichment at $\mathrm{t}=0$, from which we calculated the dilution of the tracer. Surfactant results are presented as mean \pm SEM whereas clinical data as mean \pm SD. Group comparisons were by Mann Whitney test. Correlations were obtained by Pearson correlation. The level of significance was $p<0.05$. Statistical analysis was performed with SPSS10.0 for Windows 2000 .

\section{RESULTS}

We studied 13 infants with CDH and 8 CONTROLS. Clinical characteristics of the two study groups are reported in Table 1. Mean BW, GA and postnatal ages were comparable in the two groups whereas ventilator settings differed. Seven $\mathrm{CDH}$ were diagnosed prenatally, all but one before 26 wks GA. Two of the $13 \mathrm{CDH}$ infants were right side $\mathrm{CDH}$ and 11 left side. One had associated skeletal anomalies and one had left heart hypoplasia defined according to Baumgart et al. (23). No one had chromosomal abnormalities. All but one $\mathrm{CDH}$ infants were ventilated on HFOV since birth and they were sedated and paralyzed. One was conventionally ventilated because $\mathrm{CDH}$ was diagnosed postnatally, when the chest radiograph was performed at the referring hospital. At that time the newborn was intubated and transferred to our NICU on conventional ventilation. All $\mathrm{CDH}$ infants were studied within the first $6 \mathrm{~d}$ of life. During the study period no infants showed evidence of infection. Four $\mathrm{CDH}$ infants (31\%) died before hospital discharge. One CDH died within $72 \mathrm{~h}$ from birth because of severe respiratory failure and pulmonary hypertension. The study was not completed at that time and DSPC

Table 1. Clinical characteristics of the two study groups

\begin{tabular}{|c|c|c|c|}
\hline & $\begin{array}{c}\mathrm{CDH} \\
n=15\end{array}$ & $\begin{array}{c}\text { Controls } \\
n=8\end{array}$ & $p$ \\
\hline Study weight (kg) & $3.2 \pm 0.7$ & $2.7 \pm 0.6$ & 0.1 \\
\hline Gestational age (wks) & $39 \pm 1.4$ & $38 \pm 2.4$ & 0.2 \\
\hline Postnatal age (h) & $43 \pm 40$ & $96 \pm 73$ & 0.07 \\
\hline Mechanical ventilation (days) & $10 \pm 6$ & $17 \pm 17$ & 0.3 \\
\hline Survival (\%) & $69 \%$ & $89 \%$ & 0.3 \\
\hline $\operatorname{Sex}(M / F)$ & $5 / 10$ & $4 / 4$ & 0.2 \\
\hline $\mathrm{FiO}_{2}$ at the start of the study & $0.47 \pm 0.26$ & $0.24 \pm 0.01$ & 0.006 \\
\hline Mean $\mathrm{FiO}_{2}$ during the study & $0.45 \pm 0.18$ & $0.23 \pm 0.02$ & 0.001 \\
\hline Mean $\mathrm{PaO}_{2}$ during the study & $73 \pm 19$ & $85 \pm 14$ & 0.12 \\
\hline Mean $\mathrm{PaCO}_{2}$ during the study & $41 \pm 6$ & $37 \pm 3$ & 0.26 \\
\hline Mean $\mathrm{pH}$ during the study & $7.38 \pm 0.03$ & $7.41 \pm 0.03$ & 0.02 \\
\hline $\mathrm{PaO}_{2} / \mathrm{FiO}_{2}$ at the start of the study & $223 \pm 154$ & $325 \pm 83$ & 0.03 \\
\hline Mean $\mathrm{PaO}_{2} / \mathrm{FiO}_{2}$ during the study & $219 \pm 116$ & $315 \pm 47$ & 0.04 \\
\hline Mean $\mathrm{PaCO}_{2}$ x HFOV Amplitude & $1037 \pm 335$ & & \\
\hline Mean OI & $12 \pm 5$ & $1 \pm 0.3$ & 0.0003 \\
\hline
\end{tabular}

half-life and pool size could not be determined. The other 3 $\mathrm{CDH}$ died after the study period. Two of the $3 \mathrm{CDH}$ died because of sepsis at 10 and 20 day of postnatal age, one died at 2 months for lung hypoplasia associated with vertebral and rib anomalies. None of the $\mathrm{CDH}$ survivors was oxygen dependent at hospital discharge. Of the 8 CONTROLS, 5 required mechanical ventilation for airways or oral malformations while waiting for surgery. Two had abdominal wall defects and one was ventilated because of severe intracranial bleeding. This control infant died at $10 \mathrm{~d}$ postnatal age (mortality in the control group was $12.5 \%$ ), when the study was already completed. Six newborns were mechanically ventilated and two were breathing spontaneously on room air via a tracheostomy tube. In all control infants the study was started within the first week of life. No one presented with evidence of infection during the entire study period.

The amount of DSPC from tracheal aspirates was $2.4 \pm 0.4$ $\mathrm{mg} / \mathrm{mL}$ ELF and $4.6 \pm 0.5 \mathrm{mg} / \mathrm{mL}$ ELF in CDH and CONTROLS, respectively. This difference was statistically significant with a $p$ of 0.007 . DSPC enrichment decay curves exhibit a bi-exponential pattern in all study infants. Mean \pm SEM log plot of DSPC isotopic enrichment values in CDH and CONTROLS are represented in Fig. 1. Surfactant DSPC half-life was significantly shorter and turnover significantly higher in CDH compared with CONTROLS $(24 \pm 4 \mathrm{~h}$ versus $53 \pm 11 \mathrm{~h}$, $p=0.01$ and $0.6 \pm 0.1 \mathrm{~d}^{-1}$ versus $1.5 \pm 0.3 \mathrm{~d}^{-1}, p=0.01$ respectively). (Fig. 2, $A$ and $B$ ) The apparent DSPC pool size was $34 \pm 7 \mathrm{mg} / \mathrm{kg}$ (range 13-85) in $\mathrm{CDH}$ and $57 \pm 7 \mathrm{mg} / \mathrm{kg}$ (range 42-101) in CONTROLS. The difference was statistically significant ( $p=0.02$ ). (Fig. 2, Panel C) We could not find significant correlations between any of DSPC kinetic parameters and the level of mechanical ventilation, expressed by mean airway pressure and oxygenation index, neither in the $\mathrm{CDH}$ nor in the CONTROL groups.

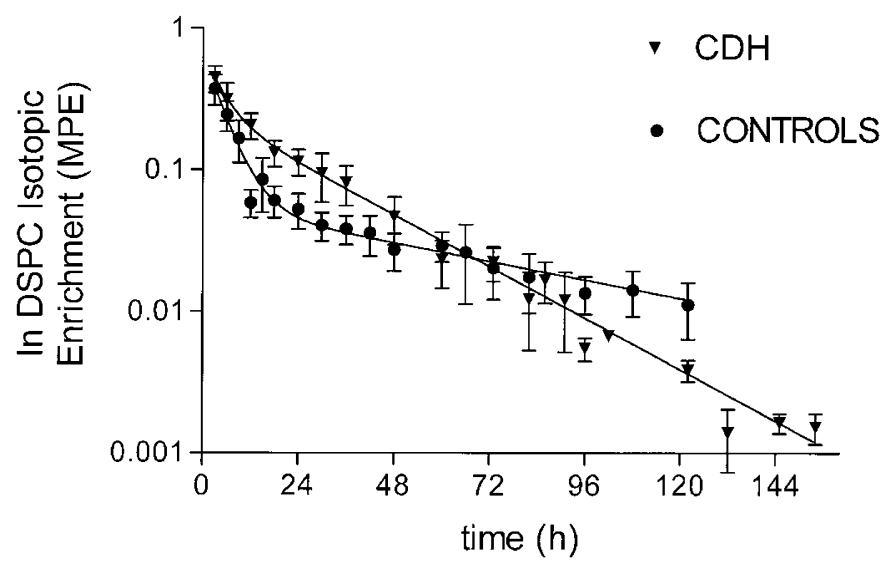

Figure 1. represents a semi-logarithmic plot of the mean isotopic enrichment values of DSPC $( \pm$ SEM) obtained from TAs against time of sampling. The $\mathrm{CDH}$ group is represented by triangles and CONTROL by circles. We recorded a rapid initial fall of the DSPC isotopic enrichment soon after the tracer administration followed by a slow long decay in both study groups, which is consistent with a bi-exponential decay curve. DSPC half-life and the apparent pool size were calculated from the final mono-exponential part of the curve, which were clearly distinguishable in all study subjects. 
A

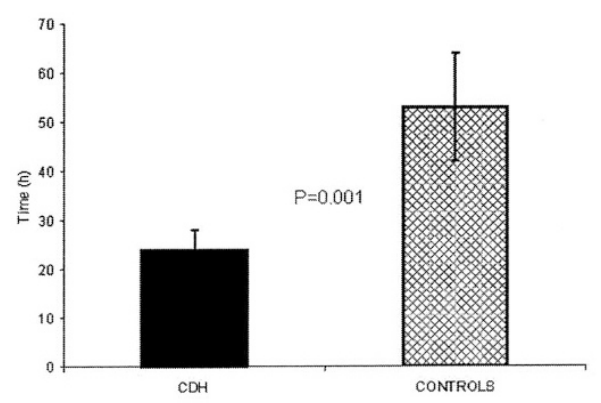

B

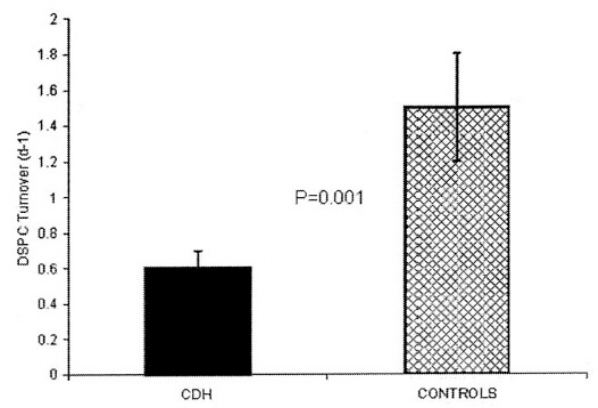

c

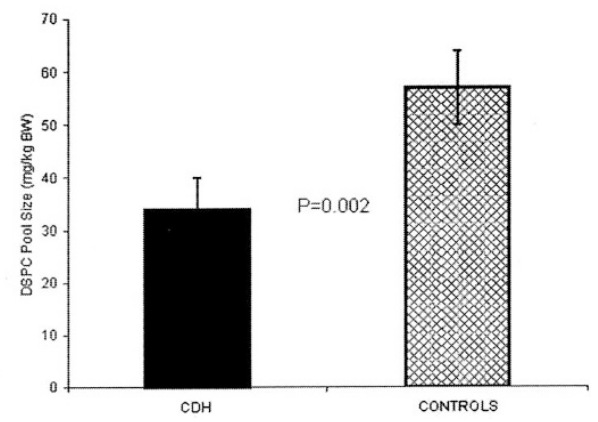

Figure 2. Histograms in panels $A, B$, and $C$ depict DSPC half-life, turnover and apparent pool size in CDH newborn infants and in age matched CONTROLS.

\section{DISCUSSION}

To the best of our knowledge this is the first study that reports significant alteration of DSPC kinetics in vivo in newborn infants with $\mathrm{CDH}$ compared with age matched controls with no lung disease. We have recently developed methods based on the safe (non-radioactive) stable isotopes that make surfactant kinetics studies ethically feasible in humans $(16,20$, 24). Stable isotope methodology provides information, which is virtually identical to that obtainable with radioactive tracers without the hazard of radioactivity (25). We measured surfactant DSPC half-life and apparent pool size in human infants with the use of stable isotope $\mathrm{U}_{-}{ }^{13} \mathrm{C}$-DPPC, which was administered endotracheally. We chose DSPC as landmark of surfactant kinetics since no biologic fluid or tissue contains such high amount of DSPC. Recent work by our group describes this method in detail, and we refer the reader to these publications where strengths and limitations are discussed (16) (26). The method has been recently validated in premature baboons by comparing half-life measurements using stable isotopes with those using radioactive DPPC and apparent pool size by stable isotopes with measurements of DSPC pool size in total lung at autopsy (27). DSPC half-lives measured by stable isotope tracer at day 5 of life and with radioactive tracer at day 8 of life were $28 \pm 4$ and $35 \pm 4 \mathrm{~h}$ respectively in 8 pre-term ventilated baboons. Apparent DSPC pool size was $129 \pm 14$ $\mu \mathrm{moL} / \mathrm{kg}$ by stable isotope methodology and $123 \pm 11$ $\mu \mathrm{moL} / \mathrm{kg}$ in total lung at autopsy by direct determination. The apparent DSPC pool size represents the volume of distribution of the stable isotope tracer, i.e. the apparent space of the body available to contain the tracer. When a small amount of tracer is given endotracheally as a bolus, we demonstrated that apparent DSPC pool size is a reasonable estimation of the total lung DSPC pool size (27).

In the present study we found that DSPC half-life was significantly shorter in $\mathrm{CDH}$ infants compared with GA and postnatal age matched controls with normal lungs. From the DSPC half-life we also calculated the DSPC turnover that represents the resident time of the tracer in the system. DSPC turnover in $\mathrm{CDH}$ infants was two-fold faster than that of our age-matched CONTROLS. A faster DSPC turnover is the consequence of a faster $\left[\mathrm{U}-{ }^{13} \mathrm{C}-\mathrm{PA}\right]$-DPPC disappearance from the DSPC pool size. Tracer disappearance can be caused either by and increased DSPC catabolism leading to a loss of stable isotope DPPC molecules, or by and increased deacylation/ reacylation pathway (recycling) (28). In the latter case the tracer palmitate produced by DSPC breakdown is reincorporated into a newly synthesized nondisaturated PC molecule, thus it is lost from the DSPC pool. Under steady state condition (16), DSPC disappearance must be equal to DSPC synthesis rate. We previously demonstrated in a similar group of $\mathrm{CDH}$ term infants that the mean DSPC fractional synthesis rate (FSR) from plasma free palmitate was $22 \%$ and $17 \%$ per day in CDH and CONTROLS respectively. The difference was not statistically significant (29). The meaning of the FSR compared with the Absolute Synthesis Rate (ASR) have been discussed at length elsewhere (30). It is noteworthy that for a given ASR a smaller pulmonary surfactant pool size results in a higher FSR. In our previous study (29) we had no information on the surfactant pool size in CDH infants. By applying the measurements of FSR of our previous study (29) to the present work we can estimate the DSPC absolute synthesis rate (ASR) from plasma palmitate or more simply DSPC synthesis. This is about $\approx 7.5 \mathrm{mg} / \mathrm{kg} / \mathrm{d}$ in $\mathrm{CDH}$ and $\approx 9.7 \mathrm{mg} / \mathrm{kg} / \mathrm{d}$ in CONTROLS with a $23 \%$ reduction of surfactant DSPC synthesis from plasma free palmitate in mechanically ventilated $\mathrm{CDH}$ newborns compared with age matched controls. This finding clearly needs to be confirmed in future studies with the measurement of endogenous surfactant synthesis and the simultaneous administration of an intra-tracheal tracer in the same patient. Synthesis from other metabolic DSPC precursors, such as acetate, ketone bodies etc, should also be measured to account for the total surfactant synthesis $(31,32)$, but, to the best of our knowledge, this information is very limited even in the animal literature.

We recently reported measurements of surfactant PC kinetics in $\mathrm{CDH}$ infants treated with ECMO in comparison with newborns on ECMO for MAS and with a third group of mechanically ventilated newborns with severe respiratory failure. PC half-lives were comparable in the three study groups. All infants presented with severe lung injury either related to the primary lung disease (MAS) or to $\mathrm{CDH}$ or secondary to mechanical ventilation and high oxygen requirement (15). We also found a faster DSPC lifespan in pre term ventilated infants at high risk of developing bronchopulmonary dysplasia (BPD) compared with GA and birth weight matched controls (26). Given that all these groups of infants were mechanically 
ventilated and on high ventilatory setting, this could support the hypothesis that a shorter DSPC half-life may not be specific of $\mathrm{CDH}$ itself but could be related to mechanical ventilation associated lung injury.

CDH infants in this study and in our previous study (29) had lower ELF-DSPC amounts compared with age-matched controls. At variance IJsselstijn et al. found no difference in PC content obtained from tracheal aspirated in $\mathrm{CDH}$ infants and compared with other newborns with respiratory failure (14). They conclude that surfactant deficiency is unlikely in $\mathrm{CDH}$ infants with severe respiratory failure. However PC is associated also with lung membrane cell and perhaps more importantly with inflammatory cells. An increased amount of PC and a decreased amount of DSPC has been described in TA and bronchoalveolar lavage of patients with acute respiratory distress syndrome or with acute lung injury (33-35).

DSPC apparent pool size in CDH was $38 \%$ lower than in CONTROLS. CDH is associated with lung hypoplasia and a lower DSPC pool size could be explained by the lower lung volume and weight. Thus it is still debatable if our data of a reduced pool size is supportive of a primary surfactant deficiency in $\mathrm{CDH}$. Moreover if a deficiency exists, this could be secondary to lung injury and inflammation $(36,37)$. The use of HFOV and paralysis in the CDH infants could also affect surfactant kinetics. In vitro studies suggest that repetitive alveolar distention, such as occurs during conventional mechanical ventilation, stimulates surfactant synthesis and secretion $(38-41)$. On the other hand, this cyclic alveolar stretch may be decreased during HFOV, which could decrease surfactant production (42-44). Recently Merchaz et al. reported similar surfactant synthesis and kinetics in preterm infants ventilated with $\mathrm{CV}$ and HFOV, suggesting that alveolar distension produced by HFOV did not decrease surfactant production (45). Work in progress by our group also support Merchaz's findings.

Janssen et al. found a PC pool size of $73 \mathrm{mg} / \mathrm{kg}$ in $8 \mathrm{CDH}$ newborns on ECMO. The apparent DSPC pool size of the $\mathrm{CDH}$ group in the present study was $34 \pm 7 \mathrm{mg} / \mathrm{kg}$ which is about half $(47 \%)$ of the PC pool size of the $8 \mathrm{CDH}$ newborns on ECMO studied by et al. (15). This difference could be explained either by the different compound measured (PC versus DSPC), or by changes in surfactant composition that occur during lung inflammation $(33,34)$. Another theoretical explanation could be that during the "lung rest" associated with ECMO surfactant catabolism is reduced while surfactant synthesis is preserved and this leads to an increased surfactant pool size.

\section{CONCLUSIONS}

In summary data on surfactant kinetics is now obtainable in $\mathrm{CDH}$ infants. We demonstrated significant alterations of surfactant kinetics in $\mathrm{CDH}$ compared with age-matched controls with no lung disease. Larger studies will ascertain if alterations of surfactant DSPC in CDH infants are related to lung dysplasia or are secondary to mechanical ventilation lung injury.

\section{REFERENCES}

1. Lotze A, Knight GR, Anderson KD, Hull WM, Whitsett JA, O'Donnell RM, Martin G, Bulas DI, Short BL 1994 Surfactant (beractant) therapy for infants with congenital diaphragmatic hernia on ECMO: evidence of persistent surfactant deficiency. J Pediatr Surg 29:407-412

2. Kavvadia V, Greenough A, Laubscher B, Dimitriou G, Davenport M, Nicolaides KH 1997 Perioperative assessment of respiratory compliance and lung volume in infants with congenital diaphragmatic hernia: prediction of outcome. J Pediatr Surg 32:1665 1669

3. Wilcox DT, Glick PL, Karamanoukian HL, Holm BA 1994 Pathophysiology of congenital diaphragmatic hernia. IX: Correlation of surfactant maturation with fetal cortisol and triiodothyronine concentration. J Pediatr Surg 29:825-827

4. Valls-i-Soler A, Alfonso LF, Arnaiz A, Alvarez FJ, Tovar JA 1996 Pulmonary surfactant dysfunction in congenital diaphragmatic hernia: experimental and clinical findings. Biol Neonate 69:318-326

5. Suen HC, Bloch KD, Donahoe PK 1994 Antenatal glucocorticoid corrects pulmonary immaturity in experimentally induced congenital diaphragmatic hernia in rats. Pediatr Res 35:523-529

6. Mysore MR, Margraf LR, Jaramillo MA, Breed DR, Chau VL, Arevalo M, Moya FR 1998 Surfactant protein A is decreased in a rat model of congenital diaphragmatic hernia. Am J Respir Crit Care Med 157:654-657

7. Utsuki T, Hashizume K, Iwamori M 2001 Impaired spreading of surfactant phospholipids in the lungs of newborn rats with pulmonary hypoplasia as a model of congenital diaphragmatic hernia induced by Nitrofan. Biochim Biophys Acta 1531:90-98

8. Iritani I 1984 Experimental study on embryogenesis of congenital diaphragmatic hernia. Anat Embryol 169:133-139

9. Lorimier AA, Thierney DF, Parker HR 1967 Hypoplastic lungs in fetal lambs with surgically produced congenital diaphragmatic hernia. Surgery 1967:12-17

10. Wilcox DT, Glick PL, Karamanoukian HL, Azizkhan RG, Holm BA 1995 Pathophysiology of congenital diaphragmatic hernia. XII: Amniotic fluid lecithin/ sphingomyelin ratio and phosphatidylglycerol concentrations do not predict surfactant status in congenital diaphragmatic hernia. J Pediatr Surg 30:410-412

11. Glick PL, Stannard VA, Leach CL, Rossman J, Hosada Y, Morin FC, Cooney DR, Allen JE, Holm B 1992 Pathophysiology of congenital diaphragmatic hernia II: the fetal lamb CDH model is surfactant deficient. J Pediatr Surg 27:382-387; discussion 387-388

12. Wilcox DT, Glick PL, Karamanoukian HL, Holm BA 1997 Contributions by individual lungs to the surfactant status in congenital diaphragmatic hernia. Pediatr Res 41:686-691

13. Nakamura Y, Yamamoto I, Fukuda S, Hashimoto T 1991 Pulmonary acinar development in diaphragmatic hernia. Arch Pathol Lab Med 115:372-376

14. IJsselstijn H, Zimmermann LJ, Bunt JE, de Jongste JC, Tibboel D 1998 Prospective evaluation of surfactant composition in bronchoalveolar lavage fluid of infants with congenital diaphragmatic hernia and of age-matched controls. Crit Care Med 26:573580

15. Janssen DJ, Tibboel D, Carnielli VP, van Emmen H, H. LI, Wattimena D, Zimmermann LJI 2003 Surfactant phosphatidylcholine pool size in human neonates with congenital diaphragmatic hernia requiring ECMO. J Pediatr 142:247-252

16. Torresin M, Zimmermann LJ, Cogo PE, Cavicchioli P, Badon T, Giordano G, Zacchello F, Sauer PJ, Carnielli VP 2000 Exogenous surfactant kinetics in infant respiratory distress syndrome: A novel method with stable isotopes. Am J Respir Crit Care Med 161:1584-1589

17. Ikegami M, Jobe A, Duane G 1985 Liposomes of dipalmitoylphosphatidylcholine associate with natural surfactant. Biochim Biophys Acta 835:352-359

18. Bligh EG, Dyer WJ 1959 A rapid method of total lipid extraction and purification. Can J Biochem Physiol 37:911-917

19. Dargaville PA, South M, Vervaart P, McDougall PN 1999 Validity of markers of dilution in small volume lung lavage. Am J Respir Crit Care Med 160:778-784

20. Cogo PE, Carnielli VP, Bunt JE, Badon T, Giordano G, Zacchello F, Sauer PJ, Zimmermann LJ 1999 Endogenous surfactant metabolism in critically ill infants measured with stable isotope labeled fatty acids. Pediatr Res 45:242-246

21. Hallman M, Merritt TA, Pohjavuori M, Gluck L 1986 Effect of surfactant substitution on lung effluent phospholipids in respiratory distress syndrome: evaluation of surfactant phospholipid turnover, pool size, and the relationship to severity of respiratory failure. Pediatr Res 20:1228-1235

22. Griese M, Dietrich P, Reinhardt D 1995 Pharmacokinetics of bovine surfactant in neonatal respiratory distress syndrome. Am J Respir Crit Care Med 152:10501054

23. Baumgart S, Paul JJ, Huhta JC, Katz AL, Paul KE, Spettell C, Spitzer AR 1998 Cardiac malposition, redistribution of fetal cardiac output, and left heart hypoplasia reduce survival in neonates with congenital diaphragmatic hernia requiring extracorporeal membrane oxygenation. J Pediatr 133:57-62

24. Bunt JEH, Zimmermann LJI, Wattimena D, van Beek R, Sauer PJJ, Carnielli VP 1998 Endogenous surfactant turnover in preterm infants measured with stable isotopes. Am J Respir Crit Care Med 157:810-814

25. Wolfe RR 1992 Radioactive and Stable Isotope Tracers in Biomedicine. Wiley-Liss, New York

26. Cogo PE, Zimmermann LJI, Pesavento R, Sacchetto E, Burighel A, Rosso F, Badon T, Verlato G, Carnielli VP 2003 Surfactant Kinetics in Preterm Infants on mechanical ventilation who did and did not developed Bronchopulmonary Dysplasia (BPD). Crit Care Med 31:1532-1538

27. Janssen DJ, Carnielli VP, Cogo PE, Seidner SR, Luijendijk IHI, Wattimena DJL, Jobe AH, Zimmermann LJI 2002 Surfactant phosphatidylcholine half-life and pool size measurements in premature baboons developing BPD. Pediatr Res 52:724-729 
28. Jobe A, Jacobs HC 1984 Catabolism of pulmonary surfactant. In: Robertson Bea (ed), Pulmonary Surfactant. Elsevier, Amsterdam, pp 271-293

29. Cogo PE, Zimmermann LJ, Rosso F, Tormena F, Gamba P, Verlato G, Baritussio A Carnielli VP 2002 Surfactant synthesis and kinetics in infants with congenital diaphragmatic hernia. Am J Respir Crit Care Med 166:154-158

30. Cavicchioli P, Zimmermann LJI, Cogo PE, Badon T, Giordano G, Torresin M, Zacchello F, Carnielli VP 2001 Endogenous surfactant turnover in preterm infants with RDS studied with stable isotope lipids. Am J Respir Crit Care Med 163:55-60

31. Sheehan PM, Yeh YY 1985 Pulmonary surfactant lipid synthesis from ketone bodies, lactate, and glucose in newborn rats. Lipids 20:835-841

32. Martini WZ, Irtun O, Chinkes DL, Barrow RE, Wolfe RR 2001 Surfactant phosphatidylcholine in thermally injured pigs. Crit Care Med 29:1417-1422

33. Schmidt R, Meier U, Yabut-Perez M, Walmrath D, Grimminger F, Seeger W, Gunther A 2001 Alteration of fatty acid profiles in different pulmonary surfactan phospholipids in acute respiratory distress syndrome and severe pneumonia. Am J Respir Crit Care Med 163:95-100

34. Nakos G, Kitsiouli EI, Tsangaris I, Lekka ME 1998 Bronchoalveolar lavage fluid characteristics of early intermediate and late phases of ARDS. Alterations in leukocytes, proteins, PAF and surfactant components. Intensive Care Med 24:296-303

35. Gunther A, Siebert C, Schmidt R, Ziegler S, Grimminger F, Yabut M, Temmesfeld B, Walmrath D, Morr H, Seeger W 1996 Surfactant alterations in severe pneumonia, acute respiratory distress syndrome, and cardiogenic lung edema. Am J Respir Crit Care Med 153:176-184

36. Jobe AH, Kramer BW, Moss TJ, Newnham JP, Ikegami M 2002 Decreased indicators of lung injury with continuous positive expiratory pressure in preterm lambs. Pediatr Res 52:387-392

37. Ikegami M, Jobe AH 2002 Injury responses to different surfactants in ventilated premature lamb lungs. Pediatr Res 51:689-695

38. Oyarzun MJ, Clemens JA 1977 Ventilatory and colinergic control of pulmonary surfactant in the rabbit. J Appl Physiol 43:39-45

39. Nicholas TE, Barr HA 1981 Control of release of surfactant phospholipids in the isolated perfused rat lungs. J Appl Physiol 51:90-98

40. Truog WE 1984 Surface active material: Influence of lung distension and mechanical ventilation on secretion. Semin Perinatol 8:300-307

41. Scott JE, Yang SY, Stanik E, Anderson IE 1993 Influence of strain on [3H] thymidine incorporation, surfactant-related phospholipid synthesis, and camp levels in fetal type II alveolar cells. Am J Respir Cell Mol Biol 8:258-265

42. Solimano A, Brian C, Jobe AH, Ikegami M, Jacobs HC 1985 Effect of high-frequency and conventional ventilation on the premature lamb lungs. J Appl Physiol 59:1571-1577

43. Ennema JJ, Reijngoud DJ, Egberts J, Mook PH, Wildevuur CR 1984 High-frequency oscillation affects surfactant phospholipid metabolism in rabbits. Respir Physiol 58:29-39

44. Dargaville PA, South M, McDougall PN 1997 Pulmonary surfactant concentration during transition from high frequency oscillator to conventional mechanical ventilation. J Paediatr Child Health 33:517-521

45. Merchaz A, Janssen DJ, Bohlin K, Patterson BW, Zimmermann LJ, Carnielli VP, Hamvas A 2002 Endogenous pulmonary surfactant metabolism is not affected by mode of ventilation in premature infants with respiratory distress syndrome. J Pediatr 140:693-698 